\title{
CARACTERÍSTICAS FÍSICO-QUÍMICAS, POLIFENÓIS E FLAVONOIDES AMARELOS EM FRUTOS DE ESPÉCIES DE PITAIAS COMERCIAIS E NATIVAS DO CERRADO ${ }^{1}$
}

\author{
CRISTIANE ANDRÉA DE LIMA², FÁBIO GELAPE FALEIRO ${ }^{3}$, \\ NILTON TADEU VILELA JUNQUEIRA ${ }^{3}$, KELLY DE OLIVEIRA COHEN ${ }^{4}$, \\ TADEU GRACIOLLI GUIMARÃES ${ }^{3}$
}

RESUMO - Apesar do grande potencial comercial da pitaia, ainda são escassos os estudos de caracterização físico-química de frutos da pitaia, principalmente considerando espécies nativas do Cerrado. Neste trabalho, objetivou-se analisar a caracterização físico-química, polifenóis e flavonoides amarelos totais de frutos de espécies de pitaia Hylocereus costaricensis, Hylocereus undatus, Selenicereus setaceus e Selenicereus megalanthus. Para as avaliações físico-químicas, foram realizadas as análises de sólidos solúveis, $\mathrm{pH}$ e acidez total titulável. Para a determinação dos compostos fenólicos, realizaram-se as análises de polifenóis extraíveis totais e flavonoides amarelos. Foram observadas diferenças significativas entre as espécies de pitaia e entre as partes basal, mediana e apical dos frutos, quanto às características físico-químicas e a concentração de compostos fenólicos. A espécie $S$. megalanthus apresentou maior quantidade de sólidos solúveis, apresentando, assim, a polpa mais doce. Tal característica foi mais pronunciada na parte mediana do fruto de todas as espécies. Houve diferença significativa entre o $\mathrm{pH}$, com valores variando de 4,84 a 5,67, classificando-se como alimentos pouco ácidos. A acidez variou de $0,10 \%$ a $0,15 \%$ de ácido cítrico. $H$. costaricensis merece destaque pela presença de maior quantidade de polifenóis totais e de flavonoides amarelos, diferenciando-se significativamente das demais espécies.

Termos para indexação: Cactaceae, variabilidade genética, melhoramento.

\section{PHYSICO-CHEMICAL CHARACTERISTICS, POLYPHENOLS AND YELLOW FLAVONOIDS IN FRUITS OF COMMERCIAL AND WILD PITAYA SPECIES FROM THE BRAZILIAN SAVANNAS}

\begin{abstract}
Although the high commercial potential of pitaya, there are yet few studies of physicochemical characterization of pitaya fruits, especially considering wild species from the Brazilian Savannas. This study was conducted with the objective to analyze the physico-chemical characterization, total polyphenols and yellow flavonoids of fruits of Hylocereus costaricensis, Hylocereus undatus, Selenicereus setaceus and Selenicereus megalanthus pitaya species. For the physico-chemical analyzes the percentage of soluble solids, $\mathrm{pH}$ value and total acidity. For the phenolic compounds quantification, total flavonoids and yellow polyphenols extractable were analyzed. Significant differences of chemical characteristics and the amount concentration of phenolic compounds were observed among pitaya species and basal, middle and apical portions of fruit. The species $S$. megalanthus had higher amounts of soluble solids. This characteristic is more pronounced in the middle part of the fruit of all species. There was significant difference of $\mathrm{pH}$, with values ranging from 4.84 to 5.67. The pitaya fruits are classified as low acid fruits. The acid content ranged from $0.10 \%$ to $0.15 \%$ of citric acid. $H$. costaricensis presented higher amount of total polyphenols and yellow flavonoids, differing significantly from the other species.
\end{abstract}

Index terms: Cactaceae, genetic variability, breeding.

\footnotetext{
'(Trabalho 274-12). Recebido em: 09-11-2012. Aceito para publicação em: 02-05-2013.

${ }^{2}$ Eng. Agr. Doutoranda em Agronomia/Universidade de Brasília, Brasília-DF. Apoio financeiro: CAPES e Embrapa Cerrados. E-mail: cristiane.andrea@yahoo.com.br.

${ }^{3}$ Pesquisador da Embrapa Cerrados, BR 020, Km 18, C. P. 08223, 73010-970. Planaltina-DF. E-mail: fabio.faleiro@embrapa.br,nilton. junqueira@embrapa.br, tadeu.graciolli@embrapa.br.

${ }^{4}$ Pesquisadora da Embrapa Sede, Departamento de Pesquisa e Desenvolvimento. Parque Estação Biológica - PqEB. Av. W3 Norte, 70770-901. Brasília/DF. E-mail: kelly.cohen@embrapa.br.
} 


\section{INTRODUÇÃO}

A pitaia é uma planta rústica da família Cactaceae e é conhecida mundialmente como "Dragon Fruit (Fruta-do-Dragão)". Existem diferentes espécies de pitaia, sendo algumas comerciais e outras nativas. De acordo com a espécie, seus frutos podem apresentar características físicas e químicas diversificadas quanto ao formato, presença de espinhos, cor da casca e da polpa, teores de sólidos solúveis e $\mathrm{pH}$ na polpa, reflexo da alta diversidade genética desta frutífera.

A pitaia pertence ao grupo de frutíferas tropicais, consideradas promissoras para o cultivo, devido à sua aparência exótica, sabor doce e suave, polpa firme e às suas propriedades nutricionais e funcionais. A pitaia é uma fruta de aceitação crescente nos mercados consumidores (MARQUES et al., 2011; MOREIRA et al., 2011). Atualmente, as principais espécies comerciais são a pitaia de casca vermelha (Hylocereus undatus) e a de casca amarela (Selenicereus megalanthus) (DONADIO, 2009).

A polpa (mesocarpo) é a parte comestível do fruto, formada por massa de textura mucilaginosa, com sementes pequenas e macias, distribuídas homogeneamente, e representa de 60 a $80 \%$ do peso dos frutos maduros. $\mathrm{O}$ rendimento de polpa, sem as sementes, representa em torno de $55 \%$ do fruto, embora maiores variações possam ser encontradas entre as diferentes espécies. Variações também podem ser observadas na acidez $(\mathrm{pH})$ e na doçura (teor de sólidos solúveis). Dentre os açúcares presentes na polpa, destacam-se a glicose e a frutose (LE BELLEC, 2006).

Entre as características físico-químicas utilizadas na avaliação da qualidade dos frutos, consideram-se as mais comuns: teor de sólidos solúveis (SS), pH, acidez total (AT) e compostos fenólicos (CHITARRA; CHITARRA, 2005). Essas características são influenciadas por diversos fatores, como as condições edafoclimáticas, tratos culturais, época e local de colheita, variedade e manuseio pós-colheita.

Apesar do grande potencial comercial dessa fruta, ainda são escassos os estudos de caracterização físico-química de frutos da pitaia, principalmente considerando espécies nativas do Cerrado. Neste trabalho, objetivou-se avaliar as características físico-químicas e a quantificação de polifenóis e flavonoides amarelos totais em diferentes porções dos frutos de quatro diferentes espécies de pitaias comerciais e nativas do Cerrado.

\section{MATERIAL E MÉTODOS}

Para realizar a caracterização físico-química e o teor de polifenóis e flavonoides amarelos totais, foram coletados ao acaso e avaliados seis frutos de quatro espécies de pitaias nativas, $H$. costaricensis, S. setaceus, H. undatus, S. megalanthus, disponíveis no Banco de Germoplasma da Embrapa Cerrados, em Planaltina-DF, latitude $15^{\circ} 35^{\prime} 00^{\prime}$ ', longitude $47^{\circ} 35^{\prime}$ 00 " e frutos comerciais das espécies $H$. undatus e $S$. megalanthus, adquiridos em mercados da região de Brasília-DF.

Os frutos foram encaminhados ao Laboratório de Ciência e Tecnologia de Alimentos da Embrapa Cerrados para a determinação de alguns parâmetros relacionados à sua composição físico-química (sólidos solúveis, $\mathrm{pH}$ e acidez total titulável) bem como para análise de polifenóis e flavonoides amarelos.

Os frutos foram lavados em água corrente, secos com papel absorvente e cortados transversalmente em três segmentos, identificados como porções basal, mediana e apical. A polpa de cada porção dos seis frutos de cada espécie foi separada da casca, homogeneizada, embalada em sacos plásticos de baixa densidade e congelada até o momento das diferentes análises.

O delineamento utilizado foi o inteiramente ao acaso, em arranjo fatorial $6 \times 3$ (6 genótipos x 3 porções do fruto), com três repetições, sendo cada repetição uma amostra retirada da polpa homogeneizada de cada porção dos seis frutos de cada genótipo.

As análises realizadas em cada amostra foram o teor de sólidos solúveis totais (\%), pelo método refratométrico, de acordo com INSTITUTO ADOLFO LUTZ, (1985), a acidez total titulável (titulação com $\mathrm{NaOH} 0,1 \mathrm{~N}$ até $\mathrm{pH}$ de 8,1), com os resultados expressos em porcentagem de ácido cítrico, e o pH, determinado por um medidor de $\mathrm{pH}$ Hanna Instruments, modelo HI 9321, calibrado periodicamente com soluções-tampão de pH 4 e 7 (AOAC, 1997). Para a determinação dos compostos fenólicos, foram realizadas análises de polifenóis extraíveis totais e flavonoides amarelos totais.

Para a extração dos polifenóis, amostras de $30 \mathrm{~g}$ foram pesadas, às quais adicionaram-se $40 \mathrm{~mL}$ de metanol:água destilada $(50 / 50, \mathrm{v} / \mathrm{v})$. As soluções foram homogeneizadas em agitador de tubos, durante 60 segundos, e permaneceram em repouso por 60 minutos à temperatura ambiente e ao abrigo da luz. Após o repouso, as soluções foram centrifugadas a $15.000 \mathrm{rpm}$, durante 20 minutos, e o sobrenadante 1 foi recolhido em um balão volumétrico de $100 \mathrm{~mL}$. Ao resíduo dessa primeira extração, foram adicionados $40 \mathrm{~mL}$ de acetona:água destilada $(70 / 30, \mathrm{v} / \mathrm{v})$, 
e repetiu-se todo o processo de homogeneização e repouso. As soluções foram centrifugadas novamente a $15.000 \mathrm{rpm}$, durante 20 minutos, o sobrenadante 2 foi recolhido e misturado ao sobrenadante $1 \mathrm{em}$ balão volumétrico de $100 \mathrm{~mL}$, completando-se o volume do extrato com água destilada (LARRAURI et al., 1997).

Em tubos de ensaio, adicionaram-se $1 \mathrm{~mL}$ do extrato, $1 \mathrm{~mL}$ de folin ciocalteau (1:3), $2 \mathrm{~mL}$ de carbonato de sódio (20\%) e $2 \mathrm{~mL}$ de água destilada, e essa solução foi homogeneizada.

A quantificação de polifenóis foi realizada em espectrofotômetro a $535 \mathrm{~nm}$, utilizando-se da curva-padrão preparada com ácido gálico (GAE - gallic acid equivalent). Os ensaios foram realizados em triplicata e em ambiente escuro, e as leituras foram realizadas aos 30 minutos, após a adição dos reagentes, e os resultados foram expressos em mg GAE. 100 $\mathrm{g}^{-1}$ de amostra fresca (OBANDA; OWUOR, 1997).

Para a determinação dos teores de flavonoides amarelos, utilizaram-se subamostras de $10 \mathrm{~g}$ de polpa, às quais foram adicionados $30 \mathrm{~mL}$ da solução extratora (etanol 95\%: $\mathrm{HCl} 1,5 \mathrm{~N}-85: 15 \mathrm{v} / \mathrm{v}$ ). Os extratos resultantes foram homogeneizados por 1 min e vertidos em balão volumétrico de $50 \mathrm{~mL}$, completando-se o volume com a mesma solução extratora. Armazenados em frascos escuros, os extratos foram refrigerados $\left(5^{\circ} \mathrm{C}\right)$ por $16 \mathrm{~h}$, em seguida foram filtrados. A leitura foi realizada em espectrofotômetro a $374 \mathrm{~nm}$, e os resultados foram expressos em $\mathrm{mg}$. $100 \mathrm{~g}^{-1}$ de amostra fresca.

Foram realizadas análises de variância, e as médias foram comparadas, utilizando o teste de Tukey, a $1 \%$ de probabilidade, com auxílio do programa Genes.

\section{RESULTADOS E DISCUSSÃO}

Pela análise de variância, verificou-se o efeito significativo de genótipos e da interação genótipo $\mathrm{x}$ porção do fruto para todas as características avaliadas, a $1 \%$ de probabilidade, pelo teste F. No caso da porção do fruto, houve efeito significativo para o teor de sólidos solúveis, acidez titulável e flavonoides amarelos (Tabela 1).

Os coeficientes de variação experimental (CVe) variaram de $1,20 \%$ para $\mathrm{pH}$, a $8,17 \%$ para flavonoides, mostrando-se de pequena amplitude, evidenciando a qualidade das análises laboratoriais.

Os coeficientes de variação genotípica $(\mathrm{CVg})$ ficaram no intervalo de $6,46 \%$ a $71,02 \%$, valores sempre superiores aos coeficientes de variação experimental, sugerindo que existe, entre os genótipos, su- ficiente variabilidade genética para ser explorada em processos de seleção e que tais caracteres são importantes quando se trata de discriminar germoplasma de pitaia. É importante mencionar que o efeito significativo de genótipos verificado no trabalho também pode ter um componente ambiental, considerando que os frutos analisados não foram produzidos no mesmo local. As frutas apresentam variações quantitativas e qualitativas nas características físico-químicas, em função de fatores intrínsecos (cultivar, variedade, estádio de maturação) e extrínsecos (condições climáticas e edáficas) (REYNERSTON et al., 2008).

A comparação das médias entre os tratamentos mostra que o teor de sólidos solúveis foi maior na porção mediana dos frutos de todas as espécies (H. costaricensis, S. setaceus, H. undatus, S. megalanthus) (Tabela 2). Como o teor de sólidos solúveis apresenta alta correlação positiva com o teor de açúcares, pode-se dizer que, no caso da pitaia, a porção mediana é a parte mais doce. Silva et al. (2002) analisaram seis espécies de frutas de clima temperado quanto ao teor de sólidos solúveis totais, separando os frutos de cada espécie em três porções: basal, mediana e apical. O kiwi apresentou maior teor de sólidos solúveis na porção basal $(11,04$ $\%$; as espécies nectarina e pera apresentaram teores maiores na porção mediana $(12,08 \%$ e $11,75 \%$, respectivamente); para as espécies ameixa, maçã e pêssego, os maiores teores foram na porção apical (16,11\%, 12,06\% e 11,38\%, respectivamente).

A espécie que apresentou maior teor de sólidos solúveis foi a $S$. megalanthus, tanto nos frutos comerciais como nos coletados no banco de germoplasma da Embrapa Cerrados, contendo 17,3 e 16,3 $\%$, respectivamente. Esta espécie merece destaque considerando que os açúcares solúveis presentes nos frutos são responsáveis pela doçura e sabor, quando combinados adequadamente com os polissacarídeos estruturais (GOMES, 2002).

Foram também verificadas diferenças significativas no $\mathrm{pH}$ entre as espécies, com valores variando de 4,83 a 5,67. Estes valores fazem com que as pitaias analisadas no presente trabalho sejam classificadas como frutos pouco ácidos. A espécie H. undatus (comercial) apresentou maior média de $\mathrm{pH}(5,70)$ e menor média de sólidos solúveis $(0,10$ $\%$ ácido cítrico), diferenciando-se significativamente das demais espécies. $\mathrm{O} \mathrm{pH}$ é um caracter importante do fruto, uma vez que pode influenciar no tempo de deterioração, através do desenvolvimento de microrganismos, na atividade das enzimas, na retenção do sabor-odor de produtos de frutas, na estabilidade de corantes artificiais em produtos de frutas, na verificação do estádio de maturação de frutas, na escolha da embalagem, na palatabilidade, na escolha da temperatura de tratamento térmico, na escolha do tipo 
de material de limpeza e desinfecção, na escolha do equipamento com o qual se vai trabalhar na indústria e na escolha de aditivos e conservantes.

Com relação à acidez, pode-se dizer que a porcentagem de acidez é baixa nos frutos de pitaia, variando de $0,10 \%$ de ácido cítrico na espécie $H$. undatus a $0,15 \%$ de ácido cítrico na espécie $S$. megalanthus. Tal diferença não foi significativa entre as médias das espécies. Também não foram verificadas diferenças muito expressivas entre a acidez das partes apical, mediana e basal dos frutos. A acidez é resultante dos ácidos orgânicos, os quais influenciam na cor, sabor, odor e na qualidade das frutas. Através da determinação da acidez total em relação ao conteúdo de açúcar, pode-se obter o estádio de maturação das frutas.

$\mathrm{O}$ valor médio de polifenóis totais obtidos dos frutos de pitaia da espécie $H$. costaricensis de $23,15 \mathrm{mg} \mathrm{GAE} 100 \mathrm{~g}^{-1}$ foi significativamente maior que o de outras espécies de pitaia (Tabela 3). A quantidade de polifenóis da espécie $H$. costaricensis foi aproximadamente $100 \%$ superior à apresentada pela espécie H. undatus (Coleção de Germoplasma Embrapa Cerrados). De acordo com Lim et al. (2007), o conteúdo fenólico total da polpa de pitaia da espécie Hylocereus polyrhizus de $21 \pm 6 \mathrm{mg}$ GAE. $100 \mathrm{~g}^{-1}$ é relativamente menor do que os obtidos por Choo et al. (2011), de $24.22 \pm 0.95 \mathrm{mg}$ GAE. $100 \mathrm{~g}^{-1}$ para a mesma espécie, e $28.65 \pm 1.79$ GAE. $100 \mathrm{~g}^{-1}$ para $H$. undatus. No entanto, Wu et al. (2006) relataram maior teor de fenólicos $(42,4 \pm 0,04$ mg GAE. 100 $\left.\mathrm{g}^{-1}\right)$ na espécie $H$. polyrhizus. Segundo esses autores, essa diferença pode ser devida à variação ambiental do crescimento ou devido à diferença de fase de maturação dos frutos.

Apesar das diferenças significativas entre a quantidade de polifenóis totais de diferentes espécies de pitaia, tal quantidade é relativamente pequena, quando comparada com a obtida em outros frutos tropicais. O valor médio de polifenóis totais obtidos dos frutos de pitaia da espécie $H$. Costaricensis, de $23,15 \mathrm{mg}$ GAE. $100 \mathrm{~g}^{-1}$, está acima do mamão (15,3 mg GAE.100 $\left.\mathrm{g}^{-1}\right)$ e abaixo do abacaxi $(85,1$ mg GAE. $\left.100 \mathrm{~g}^{-1}\right)$, da banana $(215,7 \mathrm{mg}$ GAE.100 $\left.\mathrm{g}^{-1}\right)$, da laranja $\left(114,6 \mathrm{mg}\right.$ GAE. $\left.100 \mathrm{~g}^{-1}\right)$ e da manga (110,5 mg GAE.100 g-1 ${ }^{-1}$ (FALLER; FIALHO, 2009).

A porção basal do fruto da espécie $H$. costaricensis apresentou maior quantidade de polifenóis $\left(24,71 \mathrm{mg}\right.$ GAE. $\left.100 \mathrm{~g}^{-1}\right)$. No caso das outras espécies analisadas, não foram verificadas diferenças significativas entre a quantidade de polifenóis, nas diferentes partes do fruto.

No caso dos flavonoides, novamente a espécie $H$. costaricensis apresentou a maior quantidade, em média $6,03 \mathrm{mg} .100 \mathrm{~g}^{-1}$ de flavonoides amarelos, diferenciando-se significativamente das demais espécies, valor médio de 1,89 mg. $100 \mathrm{~g}^{-1}$ de flavonoides amarelos. Este valor foi mais de 6 vezes superior ao apresentado pela espécie $S$. megalanthus nativa. A espécie nativa $S$. setaceus apresentou, em média, a segunda maior quantidade de flavonoides amarelos, com 2,97 mg.100 g-1. De acordo com Wu et al. (2006), a quantificação de flavonoides da polpa da espécie $H$. polyrhizus cultivada em Taiwan foi de $7,21 \pm 0,02 \mathrm{mg}$ de equivalentes de catequina/100 g de polpa fresca.

Em países considerados detentores de alta biodiversidade, com grande território, como o Brasil, a questão da biodiversidade de espécies nativas tem enorme relevância, ainda pouco explorada comercialmente (ALHO, 2012). Os resultados deste trabalho mostram o potencial inter e intraespecífico das espécies nativas de pitaia, valores que podem enriquecer a diversidade alimentar e nutricional da população brasileira, complementando uma dieta saudável.

TABELA 1- Resumo da análise de variância dos dados relativos às variáveis sólidos solúveis (SS), acidez titulável (AT), polifenóis extraíveis (PE), flavonoides amarelos (FLAV), avaliados em seis genótipos de Pitaia. UnB/Embrapa Cerrados, Planaltina-DF.

\begin{tabular}{ccccccc}
\hline \multirow{2}{*}{ Fontes de Variação } & \multicolumn{6}{c}{ Valores de F } \\
\cline { 2 - 7 } & GL & SS & pH & AT & PE & FLAV \\
\hline Genótipo (G) & 5 & $1215,85945^{* *}$ & $258,56973^{* *}$ & $34,18431^{* *}$ & $641,61502^{* *}$ & $679,83617^{* *}$ \\
Porção do Fruto (PF) & 2 & $322,66454^{* *}$ & 2,29188 & $10,43137^{* *}$ & 2,38079 & $12,16819^{* *}$ \\
G X PF & 10 & $15,90021^{* *}$ & $6,90881^{* *}$ & $6,61961^{* *}$ & $5,73859^{* *}$ & $5,81515^{* *}$ \\
Resíduo & 36 & 0,08722 & 0,00378 & 0,00009 & 0,26956 & 0,04463 \\
\hline Coeficiente de Determinação (\%) & - & 99,9178 & 99,6133 & 97,0747 & 99,8441 & 99,8529 \\
CVe (\%) & - & 2,1701 & 1,2074 & 7,8678 & 3,3723 & 8,1773 \\
CVg (\%) & - & 25,2128 & 6,4594 & 15,1078 & 28,4516 & 71,0182 \\
Razão CVg/CVe(\%) & - & 11,6183 & 5,3497 & 1,9202 & 8,4368 & 8,6848 \\
\hline
\end{tabular}

(CVe) - coeficientes de variação ambiental e (CVg) - coeficientes de variação genético.

**significativos a $1 \%$ de probabilidade, pelo teste $\mathrm{F}$. 


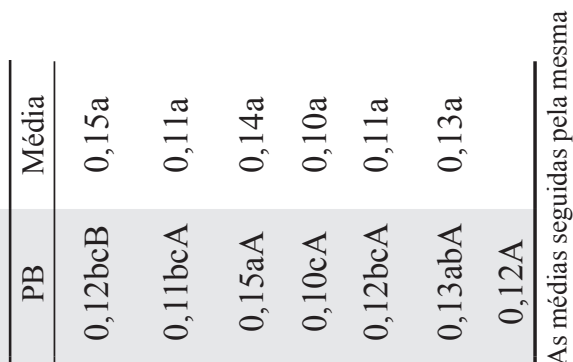

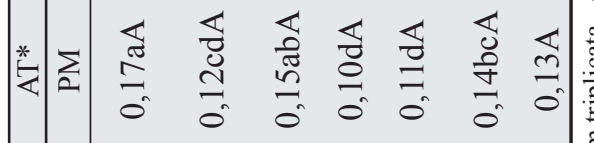

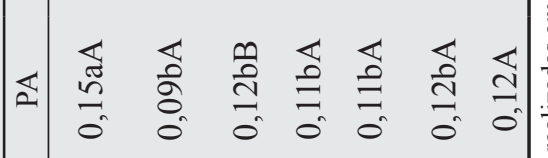

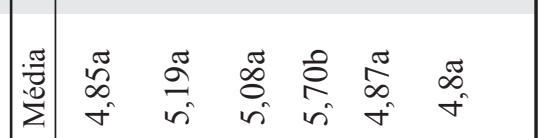

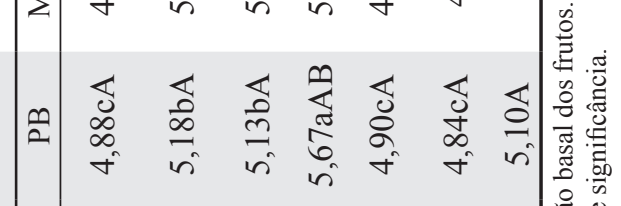

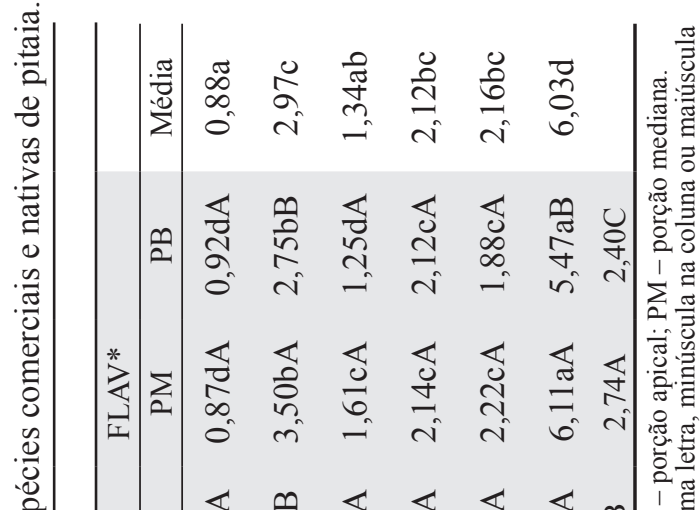

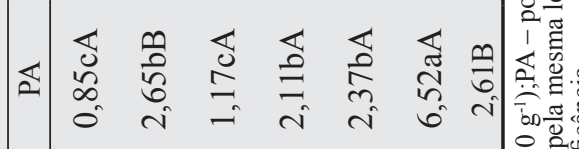

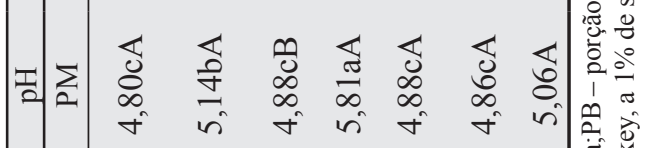

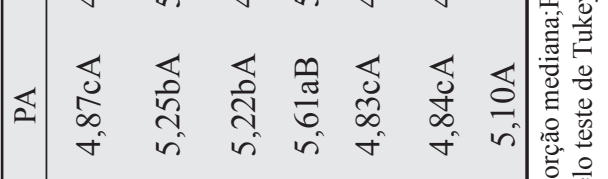

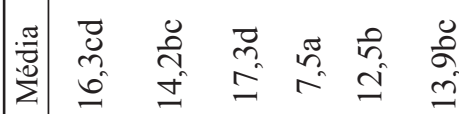

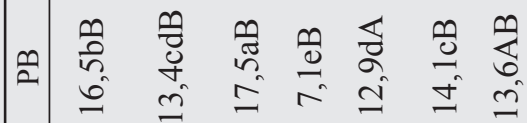

总

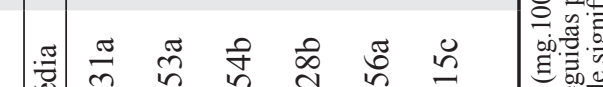

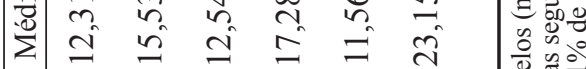

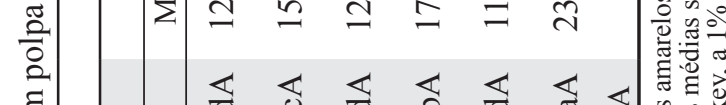

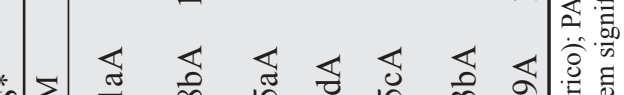

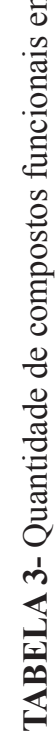

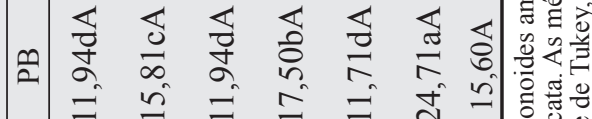

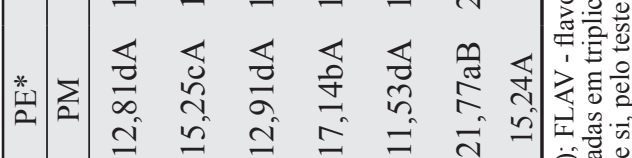

๔

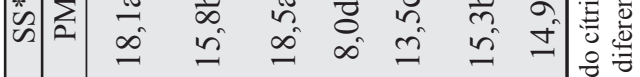

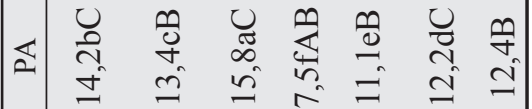

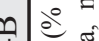




\section{CONCLUSÃO}

As quatro espécies de pitaia nativas e comerciais apresentaram diferenças nos frutos quanto às características físico-químicas e à concentração de polifenóis. A espécie Selenicereus megalanthus apresentou maior quantidade de sólidos solúveis, sendo esta característica mais pronunciada na parte mediana do fruto de todas as espécies. A espécie nativa Hylocereus costaricensis merece destaque pela presença de maior quantidade de polifenóis e flavonoides amarelos totais.

\section{REFERÊNCIAS}

ALHO, C.J.R. Importância da biodiversidade para a saúde humana: uma perspectiva ecológica. Estudos Avançados, São Paulo, v. 26, n. 74, p.151-166, 2012.

AOAC. Official methods of analysis of the Association of Official Analytical Chemists International. $16^{\text {th }}$ ed. Washington, 1997. v.2.

CHITARRA, M.I.F.; CHITARRA, A.B. Pós-colheita de frutas e hortaliças: fisiologia e manuseio. 2.ed. Lavras: UFLA, 2005. 785p.

CHOO, W.S.; YONG, W.K. Antioxidant properties of two species of Hylocereus fruits. Advances in Applied Science Research, Benha, v.2, n.3, p.418425. 2011.

DONADIO, L. C. Pitaya. Revista Brasileira de Fruticultura, Jaboticabal, v. 31, n. 3, p. 637-929, 2009.

FALLER, A.L.K.; FIALHO, E. Disponibilidade de polifenóis em frutas e hortaliças consumidas no Brasil. Revista de Saúde Pública, São Paulo, v.43, n.2, p.211-218, 2009.

GOMES, P.M. de A.; FIGUEIRÊDO, R.M.F.; QUEIROZ, A.J. de M. Caracterização e isotermas de adsorção de umidade da polpa de acerola em pó. Revista Brasileira de Produtos Agroindustriais, Campina Grande, v.4, n.2, p.157-165, 2002.

INSTITUTO ADOLFO LUTZ. Normas analíticas do Instituto Adolfo Lutz: métodos químicos e físicos para análises de alimentos. 3.ed. São Paulo, 1985. v.1, 533p.
LARRAURI, J. A.; RUPÉREZ, P.; SAURACALIXTO, F. Effect of drying temperature on the stabilitity of polyphenols and antioxidant activity of red grape pomace peels. Journal Agricultural and Food Chemistry, Washington, v. 45, n. 4, p.13901393, 1997.

LE BELLEC, F.; VAILLANT, F. ; IMBERT, E. Pitahaya (Hylocereus spp.): a new fruit crop, a market with a future. Cirad/EDP Sciences. Fruits, Paris, v.61, p.237-250, 2006.

LIM, Y.Y.; LIM, T.T.; TEE, J.J. Antioxidant properties of several tropical fruits: A comparative study. Food Chemistry, Oxford, v. 103, n.3, p.10031008, 2007.

MARQUES, V.B.; MOREIRA, R.A.; RAMOS, J.D; ARAÚJO, N.A.; SILVA, F.O.R. Fenologia reprodutiva de pitaia vermelha no município de Lavras, MG. Ciência Rural, Santa Maria, v.41, n.6, p.984-987, 2011.

MOREIRA, R.A; RAMOS, J.D.; MARQUES, V.B.; ARAÚJO, N.A.; MELO, P.C. Crescimento de pitaia vermelha com adubação orgânica e granulado bioclástico. Ciência Rural, Santa Maria, v.41, n.5, p.785-788, 2011.

OBANDA, M.; OWUOR, P.O. Flavanol Composition and Caffeine Content of Green Leaf as Quality Potential Indicators of Kenyan Black Teas. Journal of the Science of Food and Agriculture, London, v.74, p.209-215, 1997.

REYNERSTON, K.A.; YANG, H.; JIANG, B.; BASILE, M.B.; KENNELY, E. J. Quantitative analysis of antiradical phenolic constituents from fourteen edible Myrtaceae fruits. Food Chemistry, Oxford, v.109, n.4, p.883-890, 2008

SILVA, P.S.L.; SÁ, W.R.; MARIGUELE, K.H.; BARBOSA, A.P.R.; OLIVEIRA, O.F. Distribuição do teor de sólidos solúveis totais em frutos de algumas espécies de clima temperado. Caatinga, Mossoró, v.15, n. 1/2, p. 19-23, 2002.

WU, L.C.; HSU, H.W.; CHEN Y.C.; CHIU, C.C.; LIN, Y.I. HO; J.A.A. Antioxidant and antiproliferative activities of red pitaya. Food Chemistry, Oxford, v. 95, p.319-327, 2006. 